\title{
Effect of element substitution on hydrogen absorption in compounds with the structure type $\mathrm{W}_{2} \mathrm{CoB}_{2}$
}

\author{
Khrystyna MILIYANCHUK ${ }^{1}$, Ladislav HAVELA $^{2}$, Roman GLADYSHEVSKII ${ }^{1}$ \\ ${ }^{1}$ Department of Inorganic Chemistry, Ivan Franko National University of Lviv, \\ Kyryla i Mefodiya St. 6, 79005 Lviv, Ukraine \\ ${ }^{2}$ Department of Condensed Matter Physics, Charles University, \\ Ke Karlovu 5, 12116 Prague 2, Czech Republic \\ *Corresponding author. E-mail: khrystyna.miliyanchuk@lnu.edu.ua
}

Received June 3, 2019; accepted June 18, 2019; available on-line January 1, 2020 https://doi.org/10.30970/cma12.0386

Two new compounds, DyErNi ${ }_{2} \mathrm{Al}$ and ErLuCoNiAl, with the orthorhombic structure type $\mathrm{W}_{2} \mathrm{CoB}_{2}$ (Pearson symbol oI10, space group Immm) were synthesized. The intermetallics absorbed 5.2 hydrogen atoms per formula unit at room temperature under a hydrogen pressure of 570 mbar. The hydrogenation resulted in strongly anisotropic lattice expansion, prevailing along the $b$-axis and accompanied by lattice contraction along the $a$-axis, leading to a relative volume expansion of $21.2 \%$ for $\mathrm{DyErNi}_{2} \mathrm{AlH}_{5.2}$ and $17.8 \%$ for ErLuCoNiAlH $_{5.2}$. It is shown that element substitution in the positions of both $f$-and $d$-elements should be taken into account while tuning the hydrogenation properties of intermetallics.

\section{Intermetallics / Metal hydrides / Crystal structure}

\section{Introduction}

Intermetallic compounds are frequently considered as potential materials for hydrogen energy systems. The ability for reversible interaction of hydride-forming metals with hydrogen gas has resulted in the development of efficient hydrogen compressors [1]. The advantages of such devices include simplicity of design and operation, compactness, safety, and reliability. They make it possible to avoid using compressed hydrogen gas or energy-poor and unsafe liquid $\mathrm{H}_{2}$ for hydrogen storage. Besides hydrogen storage, the applications of hydride compressors include isotope handling, cryogenic/space equipment, utilization of low-grade heat, thermally driven actuators, and hydrogen refueling stations. Lototskyy et al. [1] propose a survey of intermetallic compounds used for hydrogen compression today and their quantitative parameters. A vast group of the binary representatives contain rare-earth and/or $d$-metals in different stoichiometries and crystal structures. The best materials possess features such as high compression ratio, high productivity and efficiency, long and reliable operation. It has been shown that adding certain amounts of aluminum to compounds of rare-earth and $d$-metals can affect the performance of hydrogen compressors $[2,3]$. On the example of the $\mathrm{LaNi}_{5}$ compound it has been demonstrated that substitution of aluminum for nickel can be used to tune the thermodynamic stability of the hydride. It results in a decrease of the reversible hydrogen capacity, but, on the other hand, it significantly enhances the durability of the hydride phase during extended absorption/desorption cycling.

Ternary compounds $R_{2} \mathrm{Ni}_{2} \mathrm{Al}(R=\mathrm{Gd}, \mathrm{Er}, \mathrm{Lu})$ [4] with the structure type $\mathrm{W}_{2} \mathrm{CoB}_{2}$ (space group Immm, Pearson symbol oI10 [5]) exhibit extremely rapid hydrogen absorption already at room temperature, leading to the formation of hydrides containing up to $5.5 \mathrm{H}$ at./f.u., accompanied by lattice expansion [6]. Despite the strongly anisotropic lattice expansion, the arrangement of the metal atoms is fully recovered after hydrogen desorption. Studies of the temperatureinduced desorption of the hydrides of $\mathrm{Er}_{2} \mathrm{Ni}_{2} \mathrm{Al}$ revealed two stages of hydrogen release, indicating at least two different hydrogen positions in the corresponding hydrides. With the increase of the atomic number of the rare-earth metal within the lanthanide series, the amount of absorbed hydrogen decreases, and the degree of amorphization of the hydride sample decreases. In the present paper we analyze how further multiple element substitution affects the hydrogenation properties of intermetallics with the structure type $\mathrm{W}_{2} \mathrm{CoB}_{2}$.

\section{Experimental details}

The intermetallic compounds $\mathrm{DyErNi}_{2} \mathrm{Al}$ and ErLuCoNiAl were synthesized by arc-melting of 
stoichiometric amounts of elemental metals of a purity of at least $99.9 \%$ under an argon atmosphere. To ensure homogeneity the samples were melted twice. After checking the mass for possible losses, the samples were sealed in evacuated quartz ampoules and annealed at $600^{\circ} \mathrm{C}$ for 2 months in order to reach homogeneity. Finally, the ampoules were quenched in cold water and phase analysis was carried out using powder X-ray diffraction.

Hydrogenation of the intermetallics was performed by crushing the ingots into submillimeter particles and loading these into a reactor. Prior to introducing hydrogen gas into the system, the surface of the samples was activated by heating up to $T=250^{\circ} \mathrm{C}$ for $2 \mathrm{~h}$ in oil-free vacuum $\left(p<1 \cdot 10^{-6}\right.$ mbar $)$ in order to desorb surface contaminants. Hydrogenation was performed by exposing the activated material to $\mathrm{H}_{2}$ under a pressure of $570 \mathrm{mbar}$, in the case of DyErNi ${ }_{2} \mathrm{Al}$, and $565 \mathrm{mbar}$, in the case of ErLuCoNiAl, at room temperature. The hydrogen absorption was registered by the pressure drop in a closed system, and the amount of absorbed hydrogen was obtained from the value of the pressure change. The synthesized hydrides were in the form of fine crystalline powders.
The crystal structures of the intermetallic compounds and their hydrides were studied at room temperature by powder X-ray diffraction, using a STOE Stadi $\mathrm{P}$ diffractometer $\left(\mathrm{Cu} K \alpha_{1}\right.$ radiation, $2 \theta$ range $6-110^{\circ}$, step $0.015^{\circ}$ ), or a Bruker D8 Advance diffractometer $\left(\mathrm{Cu} K \alpha\right.$ radiation, $2 \theta$ range $10-140^{\circ}$, step $0.02^{\circ}$ ). The crystal structure refinement was based on the Rietveld algorithm, using the program package FullProf Suite [7].

\section{Results and discussion}

\subsection{Crystal structures of DyErNi $i_{2} \mathrm{Al}$ and ErLuCoNiAl}

$\mathrm{X}$-ray phase analysis of the homogenized samples of compositions $\mathrm{DyErNi}_{2} \mathrm{Al}$ and ErLuCoNiAl showed that both multicomponent phases belong to the orthorhombic structure type $\mathrm{W}_{2} \mathrm{CoB}_{2}$. The crystal structures were refined within this model and the experimental, calculated and difference X-ray powder patterns are presented in Fig. 1. A few unindexed reflections indicate the presence of minor amounts of impurity phase(s). The results of the crystal structure refinements are given in Table 1.

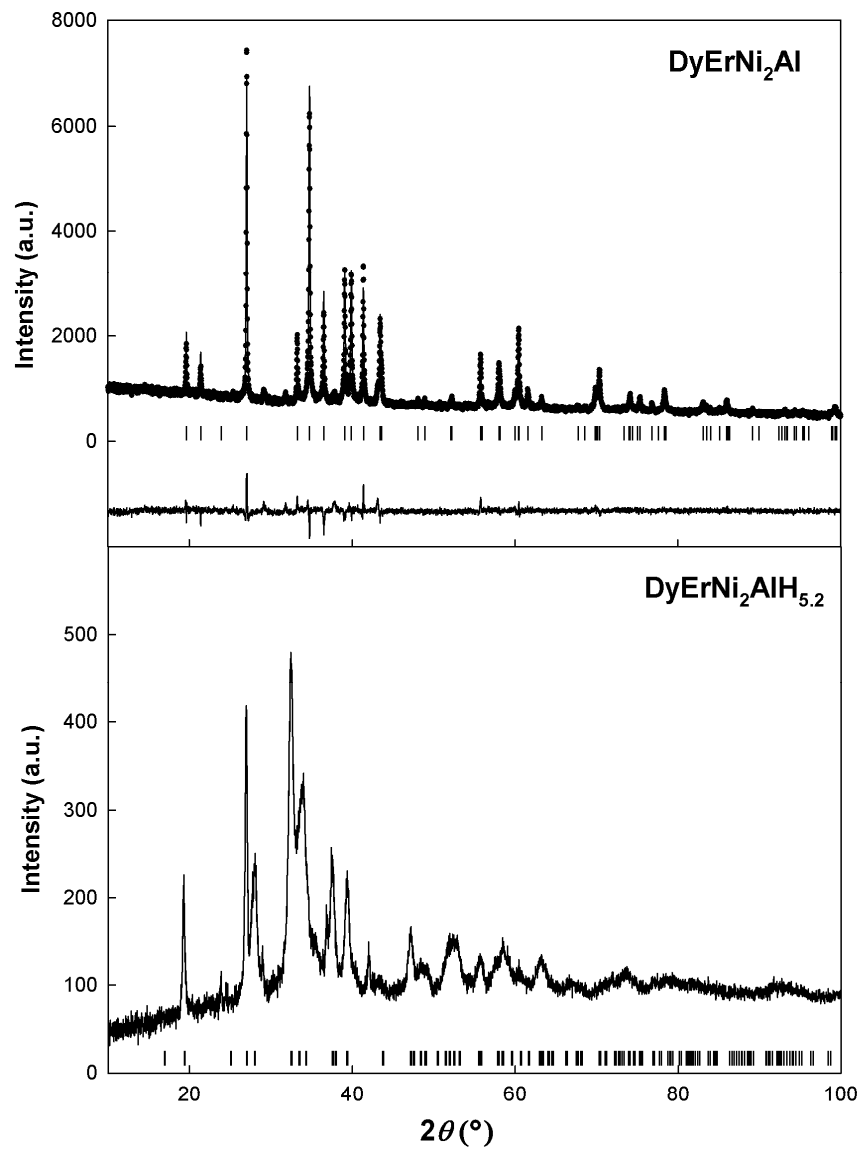

(a)

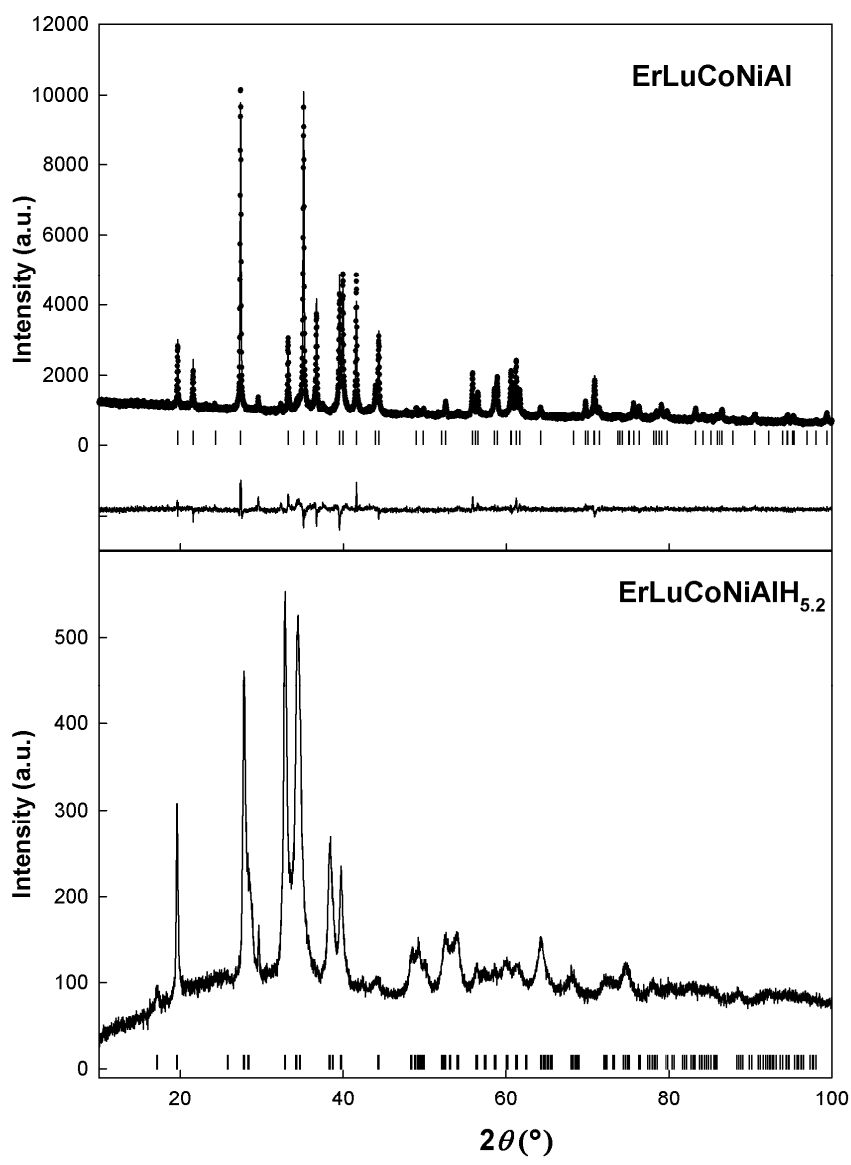

(b)

Fig. 1 X-ray powder diffraction patterns of the compounds DyErNi ${ }_{2} \mathrm{Al}$ (a) and ErLuCoNiAl (b) before (upper row panels, $\mathrm{CuK \alpha} \alpha_{1}$ radiation) and after (bottom row panels, $\mathrm{Cu} K \alpha$ radiation) hydrogenation. 
The rare-earth metal atoms form a statistical mixture and occupy the site in Wyckoff position $4 j(1 / 2,0, z)$. In the compound ErLuCoNiAl, the $\mathrm{Co}$ and $\mathrm{Ni}$ atoms also form a statistical mixture and occupy the site in Wyckoff position $4 h(0, y, 1 / 2)$, which is fully occupied by $\mathrm{Ni}$ atoms in the $\mathrm{DyErNi}_{2} \mathrm{Al}$ compound. In both compounds the $\mathrm{Al}$ atoms occupy the position $2 a$ $(0,0,0)$.

The crystal structure of the new compounds is presented in Fig. 2. The largest atoms, i.e. those of the rare-earth elements, form distorted trigonal prisms (outlined on the figure). Two sides of each prism are capped by aluminum atoms, while the third one is shared by two neighboring prisms. The nickel atoms are located inside the prisms and form pairs along the $b$-axis.

The unit-cell volumes of the new four- and fivecomponent compounds with the structure type $\mathrm{W}_{2} \mathrm{CoB}_{2}$ are consistent with the values obtained for the isotypic ternary counterparts and follow the lanthanide contraction: the unit-cell volume of DyErNi ${ }_{2} \mathrm{Al}$ lies between the values observed for $\mathrm{Gd}_{2} \mathrm{Ni}_{2} \mathrm{Al}$ and $\mathrm{Er}_{2} \mathrm{Ni}_{2} \mathrm{Al}$, and the unit-cell volume of ErLuCoNiAl between the values reported for $\mathrm{Er}_{2} \mathrm{Ni}_{2} \mathrm{Al}$ and $\mathrm{Lu}_{2} \mathrm{Ni}_{2} \mathrm{Al}$ (Table 2). On the other hand, the presence of $\mathrm{Co}$ in ErLuCoNiAl changes the ratio of the lattice parameters $a / b$ due to a smaller parameter $a$ and a larger parameter $b$, as compared to the quaternary analogue with $\mathrm{Ni}$.

Table 1 Unit-cell parameters $a, b, c, V$, atomic coordinates $x, y, z$, displacement parameters $B$ and reliability factors $R_{\mathrm{B}}, R_{\mathrm{p}}$ for the compounds DyErNi ${ }_{2} \mathrm{Al}$ and ErLuCoNiAl. Space group Immm, Pearson symbol oI 10 .

\begin{tabular}{|c|c|c|c|c|c|}
\hline Atom & Wyckoff position & $x$ & $y$ & $z$ & $B\left(\AA^{2}\right)$ \\
\hline \multicolumn{6}{|l|}{$\overline{\mathrm{DyErNi}_{2} \mathrm{Al}}$} \\
\hline \multicolumn{6}{|c|}{$a=4.1618(2) \AA, b=5.3810(3) \AA, c=8.2890(5) \AA, V=185.62(2) \AA^{3}$} \\
\hline \multicolumn{6}{|c|}{$R_{\mathrm{B}}=6.69 \%, R_{\mathrm{p}}=3.64 \%$} \\
\hline $0.5 \mathrm{Dy}+0.5 \mathrm{Er}$ & $4 j$ & $1 / 2$ & 0 & $0.2984(2)$ & $1.1(1)$ \\
\hline $\mathrm{Ni}$ & $4 h$ & 0 & $0.2394(5)$ & $1 / 2$ & $1.8(1)$ \\
\hline $\mathrm{Al}$ & $2 a$ & 0 & 0 & 0 & $1.3(3)$ \\
\hline
\end{tabular}

\section{ErLuCoNiAl}

$a=4.0813(3) \AA, \quad b=5.3893(4) \AA, c=8.2349(6) \AA, V=181.13(2) \AA^{3}$

$R_{\mathrm{B}}=7.67 \%, R_{\mathrm{p}}=3.71 \%$

\begin{tabular}{l|c|c|c|c|c}
\hline $0.5 \mathrm{Er}+0.5 \mathrm{Lu}$ & $4 j$ & $1 / 2$ & 0 & $0.2989(1)$ & $1.2(1)$ \\
$0.5 \mathrm{Co}+0.5 \mathrm{Ni}$ & $4 h$ & 0 & $0.2348(5)$ & $1 / 2$ & $1.6(1)$ \\
$\mathrm{Al}$ & $2 a$ & 0 & 0 & 0 & $0.5(2)$ \\
\hline
\end{tabular}

Table 2 Unit-cell parameters $a, b, c, V$ of aluminides with the structure type $\mathrm{W}_{2} \mathrm{CoB}_{2}$ and their hydrides, and relative lattice expansion upon hydrogenation.

\begin{tabular}{|c|c|c|c|c|c|c|c|c|c|}
\hline Compound & $a(\AA)$ & $b(\AA)$ & $c(\AA)$ & $V\left(\AA^{3}\right)$ & $\begin{array}{c}\Delta a / a \\
(\%)\end{array}$ & $\begin{array}{c}\Delta b / b \\
(\%)\end{array}$ & $\begin{array}{c}\Delta c / c \\
(\%)\end{array}$ & $\Delta V / V(\%)$ & Ref. \\
\hline$\overline{\mathrm{Gd}_{2} \mathrm{Ni}_{2} \mathrm{Al}}$ & 4.1969 & 5.4382 & 8.4484 & 192.83 & - & - & - & - & [6] \\
\hline $\mathrm{Gd}_{2} \mathrm{Ni}_{2} \mathrm{AlH}_{5.5}$ & 3.902 & 6.331 & 9.317 & 230.1 & -7.0 & 16.4 & 10.3 & 19.3 & [6] \\
\hline $\mathrm{Er}_{2} \mathrm{Ni}_{2} \mathrm{Al}$ & 4.1499 & 5.3654 & 8.2487 & 183.66 & - & - & - & - & {$[6]$} \\
\hline $\mathrm{Er}_{2} \mathrm{Ni}_{2} \mathrm{AlH}_{5.3}$ & 3.841 & 6.383 & 9.106 & 223.3 & -7.4 & 18.9 & 10.5 & 21.6 & [6] \\
\hline $\mathrm{Lu}_{2} \mathrm{Ni}_{2} \mathrm{Al}$ & 4.1158 & 5.3282 & 8.1701 & 179.17 & - & - & - & - & {$[6]$} \\
\hline $\mathrm{Lu}_{2} \mathrm{Ni}_{2} \mathrm{AlH}_{4.8}$ & 3.726 & 6.321 & 8.972 & 211.3 & -9.5 & 18.6 & 9.8 & 17.9 & [6] \\
\hline $\mathrm{DyErNi}_{2} \mathrm{Al}$ & $4.1618(2)$ & $5.3810(3)$ & $8.2890(5)$ & $185.62(2)$ & - & - & - & - & this work \\
\hline $\mathrm{DyErNi}_{2} \mathrm{AlH}_{5.2}$ & $3.855(2)$ & $6.371(3)$ & $9.160(3)$ & $225.0(2)$ & -7.4 & 18.4 & 10.5 & 21.2 & this work \\
\hline ErLuCoNiAl & $4.0813(3)$ & $5.3893(4)$ & $8.2349(6)$ & $181.13(2)$ & - & - & - & - & this work \\
\hline $\mathrm{ErLuCoNiAlH}_{5.2}$ & $3.731(1)$ & $6.297(2)$ & $9.077(2)$ & $213.3(1)$ & -8.5 & 16.8 & 10.2 & 17.8 & this work \\
\hline
\end{tabular}




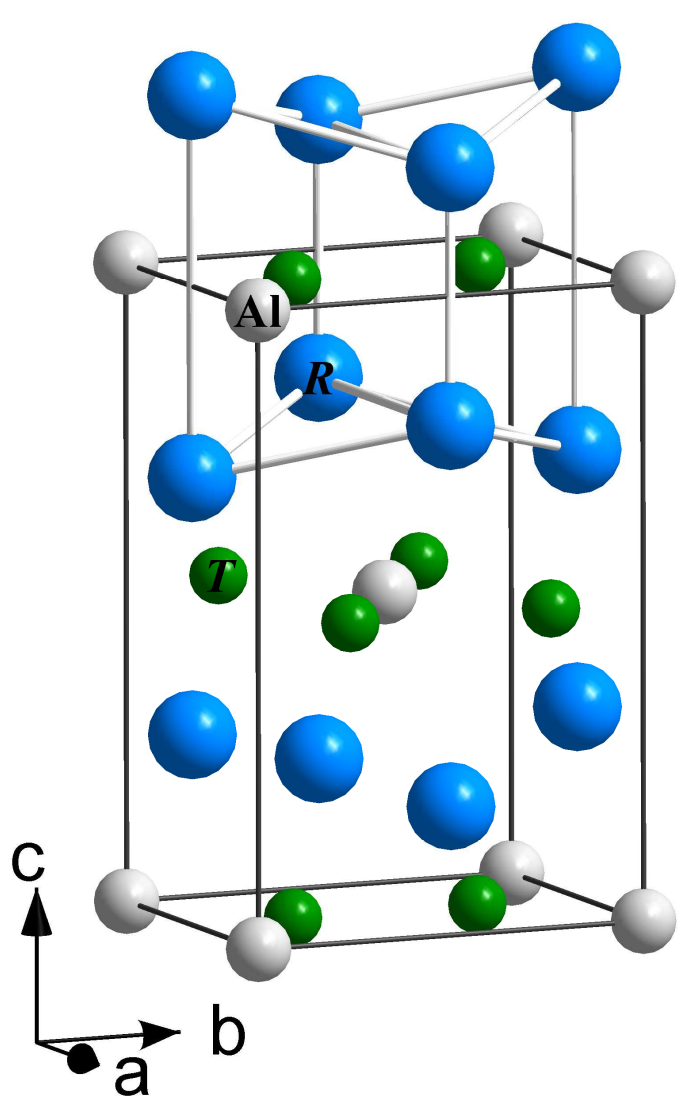

Fig. 2 Representation of the unit cell of DyErNi ${ }_{2} \mathrm{Al}$ and ErLuCoNiAl $(R-$ rare-earth element, $T-d$-element).

\subsection{Hydrogenation of $\mathrm{DyErNi} \mathrm{Al}_{2} \mathrm{Al}$ and ErLuCoNiAl}

The hydrides of $\mathrm{DyErNi}_{2} \mathrm{Al}$ and ErLuCoNiAl are easily formed at room temperature at relatively low hydrogen pressures (below 600 mbar), similarly to their ternary analogues. Hydrogenation of $\mathrm{DyErNi}_{2} \mathrm{Al}$ starts about 30 seconds after introducing hydrogen gas into the system and reaches saturation in less than 4 minutes (Fig. 3). The process is slightly more sluggish for ErLuCoNiAl: it starts after about 3 minutes and after additional 5 minutes saturation is achieved. In both cases, the reaction is strongly exothermic, which is revealed by substantial heating of the outer part of the massive steel reactor. The pressure drop in the system due to hydrogenation corresponds to 5.2(1) $\mathrm{H}$ at./f.u. for both compounds. The amount of absorbed hydrogen is in line with the values for the ternary counterparts studied earlier [6].

The X-ray powder patterns of the synthesized hydrides are shown in Fig. 1. The profile of the X-ray pattern is substantially changed upon hydrogenation, suggesting that the hydrogenation does not cause only lattice expansion. The peak broadening, which is more pronounced in the case of $\mathrm{DyErNi}_{2} \mathrm{Al}$, is a sign of smaller grain size or even partial amorphization of the sample after hydrogenation. The large peak width prevented us from determining finer details of the crystal structures of the synthesized hydrides, so we restricted ourselves to estimating the lattice expansion upon hydrogenation.

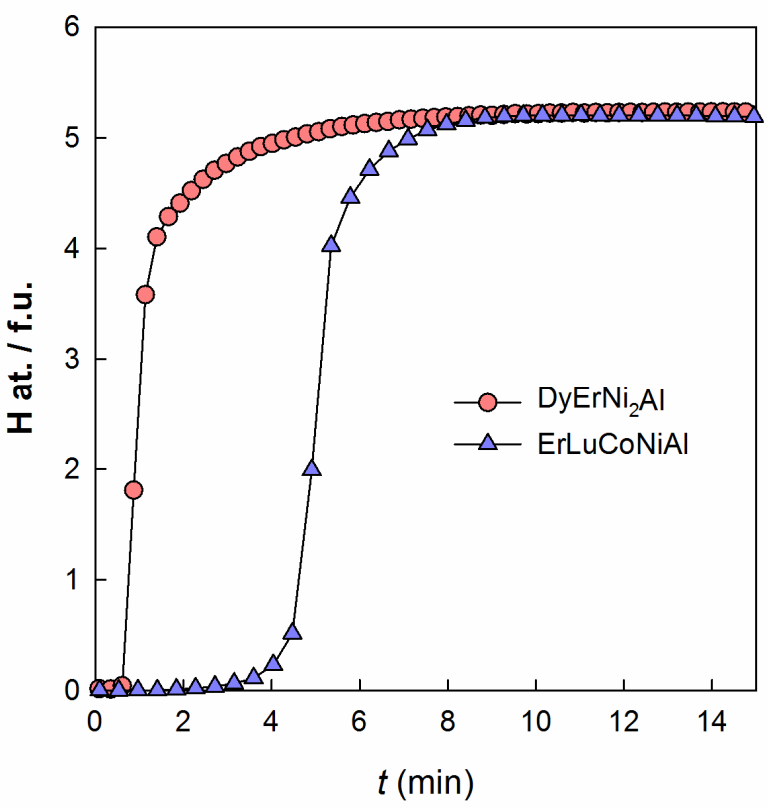

Fig. 3 Hydrogen absorption by $\mathrm{DyErNi}_{2} \mathrm{Al}$ $\left(p_{0}\left(\mathrm{H}_{2}\right)=570\right.$ mbar $)$ and ErLuCoNiAl $\left(p_{0}\left(\mathrm{H}_{2}\right)=565\right.$ mbar $)$ at room temperature as a function of time.

The X-ray powder diffraction patterns were indexed in orthorhombic symmetry like the initial intermetallics. The Bragg positions are shown as vertical lines below the experimental patterns of the hydrides in Fig. 1. The values of the lattice parameters, as well as the relative lattice expansion due to hydrogenation, are given in Table 2.

The compounds $\mathrm{DyErNi}_{2} \mathrm{Al}$ and ErLuCoNiAl continue a series of intermetallic compounds with the structure type $\mathrm{W}_{2} \mathrm{CoB}_{2}$, which exhibit strongly anisotropic cell expansion after hydrogenation. The lattice contraction along the $a$-axis is accompanied by substantial lattice expansion along the $b$-axis. The lattice expansion in the $b$-direction leads to breaking of the Ni-Ni (Ni-Co, Co-Co) pairs, while the lattice contraction in the $a$-direction results in stronger $\mathrm{Ni}-\mathrm{Al}$ ( $\mathrm{Co}-\mathrm{Al})$ interaction. Indeed, for $\mathrm{Er}_{2} \mathrm{Ni}_{2} \mathrm{Al}$ it has been shown that the nickel atoms are moved apart, and, by approaching the aluminum atoms, form infinite ribbons of edge-linked squares, centered by $\mathrm{Al}$ atoms [6]. This crystal structure belongs to the isopointal $\mathrm{K}_{2} \mathrm{PtS}_{2}$ type.

The effect of hydrogenation on $\mathrm{DyErNi}_{2} \mathrm{Al}$, i.e. the extent of the lattice deformation and the amount of hydrogen absorbed, is similar to that observed for $\mathrm{Er}_{2} \mathrm{Ni}_{2} \mathrm{Al}$. However, the presence of the larger Dy atoms leads to a higher degree of disturbance in the structure. 
In the case of the ErLuCoNiAl compound, one should take into account both substitutions, i.e. on the positions of the $f$-element atoms and on those of the $d$-element atoms. Replacement of Er atoms by smaller Lu atoms decreases the degree of amorphization of the sample after hydrogenation. The relative lattice deformations along the $a$ - and $c$-axes for ErLuCoNiAl lie between the values observed for $\mathrm{Er}_{2} \mathrm{Ni}_{2} \mathrm{Al}$ and $\mathrm{Lu}_{2} \mathrm{Ni}_{2} \mathrm{Al}$, which might indicate that these deformations are mainly defined by the nature of the rare-earth element. Differently, the relative lattice expansion along the $b$-axis does not follow the trend observed for intermetallics containing only $\mathrm{Ni}$ as $d$-element. Thus, we may assume that the interaction between $\mathrm{Ni}$ and $\mathrm{Al}$ atoms after hydrogenation is stronger than the interaction between $\mathrm{Co}$ and $\mathrm{Al}$ atoms. This would counteract the structural transition from the structure type $\mathrm{W}_{2} \mathrm{CoB}_{2}$ to the structure type $\mathrm{K}_{2} \mathrm{PtS}_{2}$. The fine details of the crystal structure of $\mathrm{ErLuCoNiAlH}_{5.2}$ will be the subject of future studies. Moreover, the presence of the smaller Lu atoms hardly decreases the hydrogen content compared to $\mathrm{Er}_{2} \mathrm{Ni}_{2} \mathrm{Al}$, as could be expected from the general trend observed for $R_{2} \mathrm{Ni}_{2} \mathrm{Al}$ hydrides; thus we attribute this effect to the presence of Co.

\section{Conclusions}

The choice of a material for a particular application presumes the fulfillment of a set of criteria. For hydrogen energy systems, one should take into account the hydrogen capacity, the reversibility of the sorption process, the stability and durability of the metal-hydride system.

On two examples of multicomponent compounds with the structure type $\mathrm{W}_{2} \mathrm{CoB}_{2}$, the diversity of the effects of element substitutions has been shown.
Concomitant negative effects (e.g. excessive amorphization or decrease of the hydrogen content) of an otherwise efficient substitution can be counterbalanced by additional element substitutions on different atomic sites. Thus, element substitution opens the way for the optimization of the hydrogenation properties of intermetallics in order to meet the requirements for applications.

\section{Acknowledgement}

This work was supported by the Ministry of Education and Science of Ukraine under the grant No. 0118 U003609.

\section{References}

[1] M.V. Lototskyy, V.A. Yartys, B.G. Pollet, R.C. Bowmen Jr., Int. J. Hydrogen Energy 39 (2004) 5818-5851.

[2] T. Kodama, J. Alloys Compd. 289 (1999) 207-212.

[3] Z. Dehouche, N. Grimard, F. Laurencelle, J. Goyette, T.K. Bose, J. Alloys Compd. 399 (2005) 224-236.

[4] R.V. Rykhal, O.S. Zarechnyuk, O.M. Marich, Dopov. Akad. Nauk Ukr. RSR, Ser. A (1978), 853-855.

[5] W Rieger, H. Nowotny, F. Benesovsky, Monatsh. Chem. 97 (1966) 378-382.

[6] K. Miliyanchuk, L. Havela, Yu. Tsaruk, S. Maškova, R. Gladyshevskii, J. Alloys Compd. 647 (2015) 911-916.

[7] J. Rodriguez-Carvajal, Commission on Powder Diffraction (IUCr), Newsletter 26 (2001) 12-19. 